\title{
Educar na sociedade de risco: o desafio de construir alternativas
}

\author{
Pedro Roberto Jacobi ${ }^{1}$ \\ Faculdade de Educação da USP e PROCAM-USP
}

resumo: Os avanços rumo a uma sociedade sustentável são permeados de obstáculos, na medida em que existe uma restrita consciência na sociedade a respeito das implicações do modelo de desenvolvimento em curso. As causas básicas das atividades ecologicamente predatórias podem ser atribuídas às instituições sociais, aos sistemas de informação e comunicação e aos valores adotados pela sociedade. A multiplicação dos riscos, em especial os ambientais e tecnológicos, de graves conseqüências, é elemento-chave para entender as características, os limites e as transformações da nossa modernidade. A sociedade, produtora de riscos, se torna crescentemente reflexiva, o que significa dizer que ela se torna um tema e um problema para si. A sociedade global "reflexiva" se vê obrigada a confrontar-se com aquilo que criou, seja de positivo ou de negativo. A reflexão sobre "sociedade de risco" nos permite estabelecer elos com a complexa temática das relações entre meio ambiente e educação, potencializando o engajamento dos diversos sistemas de conhecimento, a capacitação de profissionais e a comunidade universitária numa perspectiva interdisciplinar.

palavras-chave: Modernização reflexiva, Sociedade de risco, Desenvolvimento sustentável.

abstract: The transformations towards a sustainable society are permeated by obstacles, due to a restricted conscience by society about the implications of the existing development model. The main causes that provoke ecological predatory activities can be attributed to the social institutions, to the information and communication systems and to the values adopted by

\footnotetext{
1 e-mail: prjacobi@usp.br
} 
society. The multiplication of risks - mainly the environmental and technological ones, of serious consequences - is a key element to understand the characteristics, the limits and the transformations of our modernity. The society, as a producer of risks, becomes increasingly reflexive, what implies saying that it becomes a theme and a problem for itself. The global reflexive society is urged to confront itself with what it has created, be it positive or negative. In this text, the considerations on "risk society" allow us to establish links with the complex theme that permeates the relations between environment and education, from some parameters that are present in the practices oriented towards an "education for sustainability", increasing the engagement of several systems of knowledge and the qualification of professionals and the academic community within an interdisciplinary perspective.

keywords: Reflexive modernization, Risk society, Sustainable development.

\section{1- O Complexo Desafio da Sustentabilidade}

As noções de desenvolvimento e direitos humanos representam duas idéias de força que marcam a segunda metade do século XX. Em ambos os casos, o sistema das Nações Unidas desempenha o papel de promotor e impulsor dos processos de debate e formulação de agendas que colocam esses temas para a sociedade.

No caso do tema do meio ambiente, a sua emergência é mais recente, como conseqüência dos debates sobre os riscos de degradação ambiental, que, de forma esparsa, começaram nos anos sessenta.

A problemática da sustentabilidade assume um papel central na reflexão em torno das dimensões socioeconômicas e ambientais do desenvolvimento e das alternativas que se configuram (JACOBI, 1997; GUIMARÃES, 1998; VEIGA, 2005). Na sociedade contemporânea, a relação estabelecida entre os humanos e o meio ambiente está causando impactos cada vez mais complexos, tanto em termos quantitativos quanto qualitativos, nas condições de vida das populações, na 
capacidade de suporte planetária e na garantia da qualidade de vida das futuras gerações.

O conceito de desenvolvimento sustentável surge no contexto do enfrentamento da crise ambiental, configurada na degradação sistemática de recursos naturais e nos impactos negativos dessa degradação sobre a saúde humana. Duas correntes interpretativas se sobressaem nesse processo. Uma primeira - econômica e técnicocientífica -, que propõe a articulação do crescimento econômico e a preservação ambiental, influenciando mudanças nas abordagens do desenvolvimento econômico, notadamente a partir dos anos 70. A segunda, relacionada com a crítica ambientalista ao modo de vida contemporâneo, e que se difunde a partir da Conferência de Estocolmo, em 1972, momento no qual a questão ambiental ganha visibilidade pública e se coloca a dimensão do meio ambiente na agenda internacional. Colocaram-se em confronto duas posições: os que previam a abundância (cornucopians) e os catastrofistas (doomsayers) (SACHS, 2000, p. 50-51). Ambas foram descartadas e surge uma posição intermediária entre o economicismo determinista (prioridade ao crescimento econômico) e o fundamentalismo ecológico (inexorabilidade do crescimento do consumo e esgotamento dos recursos naturais). O paradigma do caminho do meio ecodesenvolvimento ou desenvolvimento sustentável - propunha um desenvolvimento que harmonizasse os objetivos sociais, ambientais e econômicos. A idéia ou enfoque do desenvolvimento sustentável adquire relevância num curto espaço de tempo, assumindo um caráter diretivo nos debates sobre os rumos do desenvolvimento.

Em 1973, utiliza-se pela primeira vez o conceito de ecodesenvolvimento para caracterizar uma concepção alternativa de desenvolvimento, cujos princípios foram formulados por Ignacy Sachs. Tinham como pressuposto a existência de cinco dimensões do ecodesenvolvimento: 1) a sustentabilidade social; 2) a sustentabilidade econômica; 3) a sustentabilidade ecológica; 4) a sustentabilidade espacial e 5) a sustentabilidade cultural. Esses princípios se articulam com teorias de autodeterminação defendidas pelos países não alinhados desde a década de 60 (SACHS, 1986; GUZMAN, 1997; JACOBI, 1997). 
Essas cinco dimensões refletem uma leitura que Sachs (1986) faz do desenvolvimento dentro de uma nova proposta, o ecodesenvolvimento, que propõe ações que explicitam a necessidade de tornar compatível a melhoria nos níveis de qualidade de vida com a preservação ambiental. Apresentava-se mais como uma estratégia alternativa à ordem econômica internacional, enfatizando a importância de modelos locais baseados em tecnologias apropriadas, em particular para as zonas rurais, buscando reduzir a dependência técnica e cultural. Os pressupostos do ecodesenvolvimento e outras formulações desenvolvidas nos anos setenta conseguiram introduzir a dimensão ambiental nos esquemas tradicionais de desenvolvimento econômico prevalecentes na América Latina, e a partir delas avançou-se na adoção de políticas ambientais mais estruturadas e consistentes.

O conceito de desenvolvimento sustentável formulado pela Comissão Brundtland em 1987² - "Nosso Futuro Comum" possibilita uma complexa integração conceitual entre meio ambiente e desenvolvimento, ao projetar mundialmente o termo "desenvolvimento sustentável” e o conteúdo de uma nova estratégia de desenvolvimento. A Comissão parte de uma visão complexa das causas dos problemas socioeconômicos e ecológicos da sociedade global, sublinhando as inter-relações entre economia, tecnologia, sociedade e política, e enfatiza a necessidade de uma nova postura ética que se assente na responsabilidade tanto entre gerações quanto no nosso tempo. Os resultados no início do século XXI estão muito aquém das expectativas e decorrem da complexidade de estabelecer e pactuar limites de emissões e proteção à biodiversidade, notadamente pelos países mais desenvolvidos.

Apesar das críticas a que tem sido sujeito, o conceito de desenvolvimento sustentável representa um importante avanço. O principal referencial é a Agenda 21 Global, um plano abrangente de

\footnotetext{
${ }^{2}$ Esse relatório é o resultado do trabalho da Comissão da ONU World Comission on Environment and Development, presidida por Gro Harlem Brundtland, então primeira-ministra da Noruega. A Comissão, organizada em 1983, pretendia estudar a relação entre o desenvolvimento e o meio ambiente e criar uma nova perspectiva para abordar essas questões. O Relatório "Nosso Futuro Comum”, produzido pela Comissão, foi divulgado em 1987 (MCCORMICK, 1992).
} 
ação para o desenvolvimento sustentável no século XXI, que considera a complexa relação entre o desenvolvimento e o meio ambiente e, a partir de um tripé, combina eficiência econômica com justiça social e prudência ecológica, como premissas para a construção de uma sociedade solidária e justa.

O desenvolvimento sustentável não se refere especificamente a um problema limitado de adequações ecológicas de um processo social, mas a uma estratégia ou modelo múltiplo para a sociedade, que deve levar em conta tanto uma viabilidade econômica quanto ambiental. Num sentido abrangente, a noção de desenvolvimento sustentável remete à necessária redefinição das relações sociedade humana natureza, e, portanto, a uma mudança substancial do próprio processo civilizatório. Entretanto, a falta de especificidade e as pretensões totalizadoras têm tornado o conceito de desenvolvimento sustentável difícil de ser classificado em modelos concretos e operacionais e analiticamente precisos. Por isso, ainda é possível afirmar que não se constitui num paradigma no sentido clássico do conceito, mas uma orientação ou um enfoque, ou ainda uma perspectiva que abrange princípios normativos (JACOBI, 1997; RUSCHEINSKY, 2004; GUIMARÃES, 2001).

O desenvolvimento sustentável (JACOBI, 1997) somente pode ser entendido como um processo no qual, de um lado, as restrições mais relevantes estão relacionadas com a exploração dos recursos, a orientação do desenvolvimento tecnológico e o marco institucional. A idéia de sustentabilidade implica a prevalência da premissa de que é preciso fundamentar uma limitação definida nas possibilidades de crescimento e um conjunto de iniciativas que levem em conta a existência de interlocutores e participantes sociais relevantes e ativos através de práticas educativas e de um processo de diálogo informado, o que reforça um sentimento de co-responsabilização e de constituição de valores éticos (NOORGARD, 1997; DALY, 1997; GOULET, 1997; SHENG, 1997; FLORIANI, 2003; BOFF, 1999, 2002).

Atualmente, o avanço rumo a uma sociedade sustentável é permeado de obstáculos, na medida em que existe uma restrita consciência na sociedade a respeito das implicações do modelo de 
desenvolvimento em curso. As causas básicas que provocam atividades ecologicamente predatórias podem ser atribuídas às instituições sociais, aos sistemas de informação e comunicação e aos valores adotados pela sociedade. Isso implica principalmente a necessidade de estimular uma participação mais ativa da sociedade no debate dos seus destinos, como uma forma de estabelecer um conjunto socialmente identificado de problemas, objetivos e soluções (JACOBI, 1997; GUIMARÃES, 2001).

A sustentabilidade como novo critério básico e integrador precisa estimular permanentemente as responsabilidades éticas, na medida em que a ênfase nos aspectos extra-econômicos serve para reconsiderar os aspectos relacionados com a eqüidade, a justiça social e a ética dos seres vivos.

Os anos noventa marcam mudanças significativas no debate internacional sobre os problemas ambientais. A atenção do planeta para a crise ambiental, que se inicia em Estocolmo, em 1972, atinge seu clímax no Rio de Janeiro, em 1992, quando são lançadas as bases para uma nova concepção de desenvolvimento. Representou também o primeiro passo de um longo processo de entendimento entre as nações sobre as medidas concretas visando reconciliar as atividades econômicas com a necessidade de proteger o planeta e assegurar um futuro sustentável para o mesmo.

Segundo Guimarães (2001, p. 17), o debate internacional que teve início em Estocolmo e consolidou-se no Rio supera inexoravelmente a perspectiva tecnocrática no tratamento da crise ambiental, a ilusão ingênua de que os avanços do conhecimento científico seriam suficientes para permitir a emergência de um estilo sustentável de desenvolvimento. Os problemas ambientais são os problemas do desenvolvimento, de um desenvolvimento desigual para sociedades humanas e nocivo para os sistemas naturais. Isso requer "declarar reiteradamente que os seres humanos constituem o centro, e a razão de ser do desenvolvimento requer sistemas naturais, bem como critérios superiores de respeito à dignidade humana e de melhoria na qualidade da vida das pessoas".

O quadro atual, claramente demonstrado por estudos científicos, indica que os ecossistemas continuam sentindo o impacto 
de padrões insustentáveis de produção e de urbanização. A base de recursos naturais continua sujeita às pressões antrópicas crescentes. Além disso, durante a última década, muitos países aumentaram sua vulnerabilidade a uma série mais intensa e freqüente de fenômenos que tornam mais frágeis os sistemas ecológicos e sociais, provocando insegurança ambiental, econômica e social, minando a sustentabilidade e gerando incertezas em relação ao futuro.

\section{2- Sociedade de Risco, Reflexividade e Educação}

A multiplicação dos riscos, em especial os ambientais e tecnológicos, de graves conseqüências, é elemento-chave para entender as características, os limites e as transformações da nossa modernidade. Os riscos contemporâneos (BECK, 1997, p. 16-17) explicitam os limites e as conseqüências das práticas sociais, trazendo consigo um novo elemento: a "reflexividade". A sociedade, produtora de riscos, se torna crescentemente reflexiva, o que significa dizer que ela se torna um tema e um problema para si própria. A sociedade se torna cada vez mais autocrítica, e ao mesmo tempo em que a humanidade gera perigos, reconhece os riscos que produz e reage diante disso. A sociedade global "reflexiva" se vê obrigada a confrontar-se com aquilo que criou, seja de positivo ou de negativo. O conceito de risco passa a ocupar um papel estratégico para entender as características, os limites e as transformações do projeto histórico da modernidade (BECK, id.; GUIVANT, 1998; JACOBI, 2005).

Os grandes acidentes envolvendo usinas nucleares e contaminações tóxicas de grandes proporções, como os casos de Three-Mile Island (1979), Love Canal, Bhopal (1984) e Chernobyl (1986), e outros de menor porte, mas com impactos locais significativos, aumentam o debate público e científico sobre a questão dos riscos nas sociedades contemporâneas, o que converge com a questão da cidadania e da qualidade de vida. Isso decorre do fato de os problemas ambientais e os riscos decorrentes terem crescido a passos agigantados e de a sua lenta resolução ter se tornado de conhecimento público justamente pelo seu impacto. Os riscos estão diretamente 
relacionados com a modernidade reflexiva (BECK, 1997, p. 18). O desenvolvimento do sistema industrial criou um mundo pautado pela incerteza e pela "modernização reflexiva" da alta modernidade. $\mathrm{Na}$ sociedade de risco, o impacto da globalização, as transformações do cotidiano e o surgimento da sociedade pós-tradicional se caracterizam pela sua instantaneidade, embora contraditória, que inter-relaciona o global e o local e configura novas formas de desigualdade. Os conflitos se centram em torno da produção e da distribuição de riscos, que não necessariamente são intencionais, mas resultado de um processo de modernização autônomo.

A nova realidade globalizada pós-tradicional da modernidade radicalizada gera crescente incerteza, mutabilidade e reflexividade. O progresso pode se transformar em autodestruição, um processo no qual um tipo de modernização destrói o outro e o modifica. Coloca-se, portanto, a possibilidade de se reinventar, ou repensar, a civilização industrial, ao se sugerir uma (auto)destruição criativa (BECK, 1997, p. 12-13). Observa-se uma transformação da sociedade industrial, originando a sociedade de risco. A sociedade de risco decorre da continuidade dos processos de modernização autônoma, cegos e surdos a seus próprios efeitos e ameaças.

É cada vez mais notória a complexidade desse processo de transformação crescente de uma sociedade não só ameaçada, mas diretamente afetada por riscos e agravos socioambientais.

A reflexão sobre "sociedade de risco" nos permite abordar a complexa temática das relações entre meio ambiente e educação a partir de alguns parâmetros presentes nas práticas sociais centradas na "educação para a sustentabilidade".

Num contexto marcado pela degradação permanente do meio ambiente e do seu ecossistema, a problemática envolve um conjunto de atores do universo educativo em todos os níveis, potencializando o engajamento dos diversos sistemas de conhecimento, a capacitação de profissionais e a comunidade universitária numa perspectiva interdisciplinar.

Vive-se, no início do século XXI, uma emergência, que, mais que ecológica, é uma crise do estilo de pensamento, dos imaginários 
sociais, dos pressupostos epistemológicos e do conhecimento que sustentaram a modernidade. Uma crise do ser no mundo, que se manifesta em toda a sua plenitude: nos espaços internos do sujeito, nas condutas sociais autodestrutivas e nos espaços externos, na degradação da natureza e da qualidade de vida das pessoas.

A essência da crise ambiental é a incerteza, e isto terá maior ou menor impacto de acordo com a forma como a sociedade "levanta a questão da autolimitação do desenvolvimento, assim como da tarefa de redefinir os padrões (de responsabilidade, segurança, controle, limitação do dano e distribuição das conseqüências do dano) atingidos naquele momento, levando em conta as ameaças potenciais" (BECK, 1997, p. 17).

O caminho para uma sociedade sustentável se fortalece na medida em que se desenvolvam práticas educativas que, pautadas pelo paradigma da complexidade, aportem para a escola e os ambientes pedagógicos uma atitude reflexiva em torno da problemática ambiental. $\mathrm{Na}$ medida em que o tema da sustentabilidade confronta-se com o paradigma da "sociedade de risco", isso demanda a necessidade de se multiplicarem as práticas sociais baseadas no fortalecimento do direito ao acesso à informação e à educação em uma perspectiva integradora.

\section{Práticas Educativas e a questão ambiental na contemporaneidade}

As práticas educativas nos apontam para propostas pedagógicas centradas na conscientização, mudança de comportamento e atitudes, desenvolvimento de competências, capacidade de avaliação e participação dos educandos. Isso desafia a sociedade a elaborar novas epistemologias que possibilitem o que Morin (2003) denomina de "uma reforma do pensamento" (FLORIANI, 2003, p. 116). Uma mudança paradigmática implica transformação de valores.

As iniciativas planetárias para pactuar práticas de educação orientadas para a sustentabilidade explicitam o desafio de construção de uma formulação conceitual que estabeleça uma comunicação entre ciências sociais e exatas. Nessa direção, o paradigma da complexidade corresponde à irrupção dos antagonismos no seio dos fenômenos 
organizados, uma visão complexa do universo através de certos princípios de inteligibilidade unidos uns aos outros (FLORIANI, 2003).

Refletir sobre a complexidade ambiental (MORIN, 2007) abre um estimulante espaço para compreender a formação de novos atores sociais que se mobilizam para a apropriação da natureza, para um processo educativo articulado e comprometido com a sustentabilidade e a participação, apoiado no diálogo de áreas do conhecimento. Mas também questiona valores e premissas que norteiam as práticas sociais prevalecentes, o que implica uma mudança na forma de pensar, uma transformação do conhecimento e das práticas educativas.

A premissa que norteia o paradigma proposto é o diálogo de saberes que permita construir espaços de fronteiras (SAUVÉ, 1999, p. 19-20) que nos confrontem com os diversos reducionismos e pragmatismos conceituais.

O desafio é orientar de forma decisiva as gerações atuais não somente para aceitar a incerteza e o futuro, mas para gerar um pensamento complexo e aberto às indeterminações, às mudanças, à diversidade e à possibilidade de construir e reconstruir um processo contínuo de novas leituras e interpretações.

Entende-se que as práticas educacionais inseridas na interface dos problemas socioambientais são parte do macrossistema social, subordinando-se ao contexto de desenvolvimento existente que condiciona sua direção pedagógica e política. Referimo-nos à educação ambiental, situando-a num contexto mais amplo, o da educação para a cidadania, como elemento determinante para a consolidação de sujeitos cidadãos (JACOBI, 2000). O principal eixo de atuação deve buscar, acima de tudo, a solidariedade, a igualdade e o respeito à diferença através de formas democráticas de atuação baseadas em práticas interativas e dialógicas. Entende-se que a educação para a cidadania trata não só da capacidade de o indivíduo exercer os seus direitos nas escolhas e nas decisões políticas, como ainda de assegurar a sua total dignidade nas estruturas sociais. Desse modo, o exercício da cidadania implica autonomia e liberdade responsável, participação na esfera política democrática e na vida social. 
Nossa argumentação visa reforçar a premissa de que as práticas educativas articuladas com a problemática ambiental não devem ser vistas mais como componente de um processo educativo que reforce um pensar da educação e dos educadores orientados para a sustentabilidade. Trata-se de formar um pensamento crítico, criativo e sintonizado com a necessidade de propor respostas para o futuro, capaz de analisar as complexas relações entre os processos naturais e sociais e de atuar no ambiente em uma perspectiva global, respeitando as diversidades socioculturais. O objetivo é propiciar novas atitudes e comportamentos face ao consumo na nossa sociedade e de estimular a mudança de valores individuais e coletivos (JACOBI, 1997, 2005).

$\mathrm{Na}$ ótica da modernização reflexiva, a educação ambiental tem de enfrentar a fragmentação do conhecimento e desenvolver uma abordagem crítica e política, mas reflexiva.

Portanto, a dimensão ambiental representa a possibilidade de lidar com conexões entre diferentes dimensões humanas, abrindo espaço para entrelaçamentos e múltiplos trânsitos entre múltiplos saberes. Atualmente, o desafio de fortalecer uma educação para a cidadania ambiental convergente e multirreferencial se coloca como prioridade para viabilizar uma prática educativa que articule de forma incisiva a necessidade de se enfrentar concomitantemente a crise ambiental e os problemas sociais. Assim, o entendimento sobre os problemas ambientais através da visão do meio ambiente como um campo de conhecimento e significados socialmente construídos é perpassado pela diversidade cultural e ideológica e pelos conflitos de interesse.

Aos educadores(as) caberá maior preparação para reelaborar as informações que recebem, entre elas as ambientais, a fim de poder transmitir e decodificar para os alunos a expressão dos significados em torno do meio ambiente nas suas múltiplas determinações e intersecções. A ênfase deve estar na capacitação para perceber as relações entre as áreas e estas como um todo, enfatizando uma formação local/global e buscando explicitar a necessidade de enfrentar a lógica da exclusão e das desigualdades.

As experiências interdisciplinares são recentes e incipientes, inclusive em nível de pós-graduação. $O$ que prevalece são práticas 
multidisciplinares, e, segundo Tristão (2002, p. 175), “...como as disciplinas de geografia e biologia têm uma afinidade de conteúdos em relação à dimensão ambiental, a inserção da EA ocorre por meio de um exercício multidisciplinar, às vezes até de uma cooperação entre os conteúdos dessas disciplinas".

O desafio da interdisciplinaridade é enfrentado como um processo de conhecimento que busca estabelecer cortes transversais na compreensão e explicação do contexto de ensino e pesquisa com o fito de obter a interação entre as disciplinas e superar a compartimentalização científica provocada pela excessiva especialização. Enquanto combinação de várias áreas de conhecimento, a interdisciplinaridade pressupõe o desenvolvimento de metodologias interativas, configurando a abrangência de enfoque, contemplando uma nova articulação das conexões entre as ciências naturais, sociais e exatas.

A preocupação em consolidar uma dinâmica de ensino e pesquisa a partir de uma perspectiva interdisciplinar enfatiza a importância dos processos sociais que determinam as formas de apropriação da natureza e suas transformações através da participação social na gestão dos recursos ambientais. Para tanto, deve levar-se em conta a dimensão evolutiva no sentido mais amplo, incluindo as conexões entre a diversidade biológica e cultural, assim como as práticas dos diversos atores sociais e o impacto da sua relação com o meio ambiente.

A ênfase na interdisciplinaridade da análise das questões ambientais deve-se à constatação de que os problemas que afetam e mantêm a vida no nosso planeta são de natureza global e que suas causas não podem restringir-se apenas aos fatores estritamente biológicos, revelando dimensões políticas, econômicas, institucionais, sociais e culturais.

Não é suficiente reunir diferentes disciplinas para o exercício interdisciplinar. Este deve apoiar-se em trocas sistemáticas e no confronto de saberes disciplinares que incluam não apenas uma problemática nas interfaces entre as diversas ciências naturais e sociais. Isso só se poderá concretizar a partir de uma ação orgânica das diversas disciplinas, superando a visão multidisciplinar. 
Posto que os problemas ambientais transcendem as diferentes disciplinas, tanto o aprofundamento disciplinar quanto a ampliação do conhecimento entre as disciplinas são elementos fundamentais, porém de grande complexidade quanto à sua implementação.

Uma realidade socioambiental complexa exige crescentemente a internalização de um saber ambiental emergente num conjunto de disciplinas visando construir um campo de conhecimento capaz de captar as multicausalidades e as relações de interdependência dos processos de ordem natural e social que determinam as estruturas e mudanças socioambientais.

\section{Conclusões}

O desafio político da sustentabilidade, apoiado no potencial transformador das relações sociais, encontra-se estreitamente vinculado ao processo de fortalecimento da democracia e da construção da cidadania ambiental. Nesse sentido, o papel dos educadores professores(as) é peça essencial para impulsionar as transformações de uma educação que assume um compromisso com a formação de valores de sustentabilidade, numa perspectiva coletiva.

A necessidade de uma crescente internalização da questão ambiental, um conhecimento ainda em construção, demanda um esforço de fortalecer visões integradoras que, centradas no desenvolvimento, estimulem uma reflexão em torno da diversidade e da construção de sentidos nas relações indivíduos-natureza, dos riscos ambientais globais e locais e das relações ambiente-desenvolvimento.

Nesse contexto, a educação para a cidadania ambiental aponta para a necessidade de elaboração de propostas pedagógicas centradas na conscientização, mudança de atitude e comportamento, desenvolvimento de competências, capacidade de avaliação e participação dos educandos. A relação entre meio ambiente e educação para a cidadania assume um papel cada vez mais desafiador, demandando a emergência de novos saberes para apreender processos sociais que se complexificam e riscos ambientais que se intensificam. Nas suas múltiplas possibilidades, abre um estimulante espaço para um 
repensar das práticas sociais e do papel dos professores educadores e capacitadores como mediadores e como transmissores de um conhecimento necessário. O desafio é os alunos adquirirem uma base adequada de compreensão essencial do meio ambiente global e local, da interdependência dos problemas e soluções e da importância da responsabilidade de cada um para construir uma sociedade planetária mais eqüitativa e ambientalmente sustentável.

\section{Referências bibliográficas}

BECK, Ulrich. Risk Society. London: Sage Publications, 1994.

A Reinvenção da Política. In: GIDDENS, Anthony et al. Modernização Reflexiva. São Paulo: Editora UNESP, 1997.

BOFF, Leonardo. Saber cuidar: ética do humano, compaixão pela terra. Petrópolis: Vozes, 1999.

Um ethos para salvar a Terra. In: CAMARGO, Aspásia et al. Meio ambiente Brasil: avanços e obstáculos pós-Rio-92. São Paulo: Estação Liberdade/ISA, 2002. p. 49-56.

CAPRA, Fritjof. As conexões ocultas. São Paulo: Cultrix, 2003.

CARVALHO, Isabel. Os sentidos do 'ambiental': a contribuição da hermenêutica à pedagogia da complexidade. In: LEFF, Enrique (org.). A complexidade ambiental. São Paulo: Cortez Editora, 2003.

DALY, Herman. Políticas para o desenvolvimento sustentável. In: CAVALCANTI, Clóvis (org.). Meio Ambiente, Desenvolvimento Sustentável e Políticas Públicas. São Paulo: Cortez Editora, 1997. 
FLORIANI, Dimas. Conhecimento, Meio Ambiente e Globalização. Curitiba: Juruá Editora, 2003.

FLORIANI, Dimas; KNECHTEL, Maria do Rosário. Educação Ambiental, Epistemologia e metodologias. Curitiba: Vicentinas, 2003.

GUIMARÃES, Roberto. Modernidad, medio ambiente y etica. In: Ambiente e Sociedade, Campinas, Nepam/Unicamp, 1998, ano I no 2, p. 5-24.

- La sostenibilidad del desarrollo entre Rio-92 y Johanesburgo 2002: eramos felices y no sabiamos. In: Ambiente e Sociedade, Campinas: Nepam, 2001, no 9, p. 5-24.

GUIVANT, Julia. A trajetória das análises de risco: da periferia ao centro da teoria social. In: Revista Brasileira de Informação Bibliográfica em Ciências Sociais. Rio de Janeiro: Relume Dumará, 1998.

GOULET, Denis. Desenvolvimento autêntico: fazendo-o sustentável. In: CAVAlCANTI, Clóvis (org.). Meio Ambiente, Desenvolvimento Sustentável e Políticas Públicas. São Paulo: Cortez Editora, 1997.

GUZMAN, Eduardo. Origem, evolução e perspectivas do desenvolvimento sustentável. In: ALMEIDA, Jalcione; NAVARRO, Zander. Reconstruindo a agricultura idéias e ideais na perspectiva do desenvolvimento rural sustentável. Porto Alegre: Editora UFRGS, 1997. p.19-32.

JACOBI, Pedro R. Meio ambiente urbano e sustentabilidade: alguns elementos para a reflexão. In: CAVALCANTI, Clóvis (org.). Meio Ambiente, Desenvolvimento Sustentável e Politicas Públicas. São Paulo: Cortez Editora, 1997.

(org.). Ciência Ambiental - os desafios da interdisciplinaridade. São Paulo: Annablume Editora, 1999. . Políticas Sociais e Ampliação da Cidadania. Rio de Janeiro: FGV Editora, 2000. 
- Meio ambiente e redes sociais: dimensões intersetoriais e complexidade na articulação das práticas coletivas. In: Revista de Administração Pública, vol.34(6), p. 131158. Rio de Janeiro: Fundação Getúlio Vargas, 2000,

. Educação ambiental, cidadania e sustentabilidade. In: Cadernos de Pesquisa. São Paulo: Autores Associados, 2003, n. 118, p. 189-205.

- Educação ambiental: o desafio da construção de um pensamento crítico, complexo e reflexivo. In: Educação e Pesquisa, vol.31/2. FEUSP, São Paulo. pp. 233250, ,maio/agosto 2005.

LEFF, Enrique. Pensar a complexidade Ambiental. In: (org.). A Complexidade Ambiental. São Paulo: Cortez Editora, 2003.

MCCORMICK, John. Rumo ao Paraíso. Rio de Janeiro: Relume Dumará, 1992. cap. 1 a 4.

MORIN, Edgar et al. Educar na era planetária. São Paulo: Cortez Editora, 2003.

MORIN, Edgar. Ciência com Consciência. Rio de Janeiro: Bertrand Brasil, 2007.

NOORGARD, Richard. Valoração ambiental na busca de um futuro sustentável. In: CAVALCANTI, Clóvis (org.). Meio Ambiente, Desenvolvimento Sustentável e Políticas Públicas. São Paulo: Cortez Editora, 1997.

RUSCHEINSKY, Aloisio. Sustentabilidade: uma paixão em movimento. Porto Alegre: Sulina, 2004. p. 15-33.

SACHS, Ignacy. Ecodesenvolvimento: Crescer sem destruir. São Paulo: Vértice, 1986. . Caminhos para o desenvolvimento sustentável. Rio de Janeiro: Garamond, 2000.

SAUVÉ, Lucie. La educación ambiental entre la modernidad y la posmodernidad: en busca de un marco educativo integrador. In: Tópicos en Educación Ambiental. México: Semarnap, 1999. 
SHENG, Fulai. Valores em mudança e construção de uma sociedade sustentável. In: CAVAlCANTI, Clóvis (org.). Meio Ambiente, Desenvolvimento Sustentável e Políticas Públicas. São Paulo: Cortez Editora, 1997.

TRISTÃO, Martha. As dimensões e os desafios da educação ambiental na sociedade do conhecimento. In: RUSCHEINSKY, Aloisio (org.). Educação Ambiental Abordagens Múltiplas. Porto Alegre: Artmed Editora, 2002.

VEIGA, José Eli. Desenvolvimento Sustentável: o desafio do século XXI. Rio de Janeiro: Garamond, 2005. 
